Article

\title{
Pressure Drop and Void Fraction in Horizontal Air-Water Stratified Flows with Smooth Interface at Atmospheric Pressure
}

\author{
Igor Matteo Carraretto, Luigi Pietro Maria Colombo $\mathbb{D}^{\text {, Damiano Fasani, Manfredo Guilizzoni * }}$ \\ and Andrea Lucchini \\ Department of Energy, Politecnico di Milano, via Lambruschini 4, 20156 Milano, Italy; \\ igormatteo.carraretto@polimi.it (I.M.C.); luigi.colombo@polimi.it (L.P.M.C.); damiano.fasani@polimi.it (D.F.); \\ andrea.lucchini@polimi.it (A.L.) \\ * Correspondence: manfredo.guilizzoni@polimi.it; Tel.: +39-02-2399-3888
}

Received: 5 June 2020; Accepted: 26 June 2020; Published: 29 June 2020

check for updates

\begin{abstract}
This work presents and analyses the results of an experimental activity aimed at the characterization of stratified air-water flow conditions, which have been poorly analyzed in previous studies although they are significant for industrial applications. Tests were performed in a $24 \mathrm{~m}$ long, $60 \mathrm{~mm}$ inner diameter PMMA pipe; the superficial velocities ranged between $0.03 \mathrm{~m} / \mathrm{s}$ and $0.06 \mathrm{~m} / \mathrm{s}$ for the water and between $0.41 \mathrm{~m} / \mathrm{s}$ and $2.31 \mathrm{~m} / \mathrm{s}$ for air. The pressure gradient along the pipeline was determined and compared to the one obtained implementing two-fluid models available in the literature. Fair agreement with the models was found only at high values of the superficial gas velocities, i.e., above $1.31 \mathrm{~m} / \mathrm{s}$. Moreover, the void fraction was measured through a resistive probe and compared with the values predicted by available models. Since none of them was able to satisfactorily predict the void fraction in the whole range of superficial velocities, a drift flux model was successfully implemented. Eventually, with both the measured pressure gradient and the void fraction, a two-fluid model was implemented in order to determine the interfacial shear stress and to compare the outcome with the literature, emphasizing the influence of the operating conditions on the prediction performance.
\end{abstract}

Keywords: two-fluid flow; pressure drop; void fraction

\section{Introduction}

The global interest in the study of multiphase flow has progressively grown in the last century since multiphase mixtures are widely encountered nowadays in industrial processes and they represent a crucial matter to be analyzed for the development and the optimization of many industrial processes [1,2].

In particular, from the 1970s onward, multiphase flow has been studied extensively in order to provide engineers with suitable design tools [1]. A significant aspect in the characterization of a multiphase flow is represented by the flow pattern, i.e., the variety of configurations taken by the two phases during the flow. Different flow patterns strongly influence transport phenomena and therefore they have been recognized and classified and integrated, where significant, within the models in order to achieve a consistent improvement in their accuracy.

Regarding air-water adiabatic flows in horizontal ducts at atmospheric pressure, object of this paper, Mandhane et al. [3] provided a useful map, identifying six different flow patterns as a function of the superficial velocities of the phases.

This work analyses the stratified region of the flow map, corresponding to low superficial velocities of both gas and liquid phases, which is of particular interest in many industrial areas. As remarkable 
examples can be mentioned gas transportation lines [4], geothermal plants and particular operating conditions of pressurized water nuclear reactors and chemical plants [2,5]. From the early work by Mandhane et al. [3], several authors provided a more detailed classification of the stratified flow pattern. In particular, Spedding and Nguyen [6], Andritsos and Hanratty [7] and, more recently, Tzotzi et al. [8] identified four sub-regimes mainly differing in the shape of the interface. Specifically, at constant liquid superficial velocity, raising the gas superficial velocity, the smooth gas-liquid interface is perturbed such that initially two-dimensional "ripple" waves appear, evolving to three-dimensional "roll" waves and then growing to inertial waves. After that, liquid drop entrainment in the gas or air bubble entrainment in the liquid [9] may take place as a beginning of transition to pseudo-slug and slug flow [10]. Particular attention has been devoted to the mechanism of interfacial waves formation and their description [10-13], since they significantly affect interphase mass, momentum and heat transfer, and in turn the global fluid dynamic behavior characterized by pressure drop and void fraction.

Turning the attention to modelling, the typical engineering approach is based on the one-dimensional two-fluid model [14], involving in the most general case six equations for the conservation of mass, momentum and energy of the two phases. In many of the works published in the literature and concerning the present paper [15-17], the following assumptions greatly simplify the mathematical statement of the problem:

1. Steady state;

2. Fully developed flow conditions;

3. Adiabatic or isothermal flow;

4. Constant properties of the phases.

In particular, regarding stratified gas-liquid flows without heat transfer, phase change and with negligible entrainment of the phases, the momentum balance equations can be solved to derive the pressure gradient and the phase holdup, as reported in the early models by Govier and Aziz, [15] Agrawal et al. [16], Taitel and Dukler [17], which only differ in minor details. Other authors studied the stratified flow regimes with particular attention to the interfacial stability during stratified to wavy [18-20] and wavy to slug [21] flow pattern transition. Over the years, particular attention was also paid to the analysis of flow conditions with a small amount of liquid, i.e., void fraction higher than $90 \%$ (e.g., [22-28]), with the aim of modelling gas flowlines with a very small amount of liquid deposition/accumulation. Actually, as remarked above, the presence of waves at the interface significantly changes the interfacial shear stress and hence the momentum transfer between the phases, leading to very different behaviors of both phase holdups and pressure gradients compared to the case of smooth interface. In this respect, Tzotzi and Andrisitos [29] recently provided semi-empirical models for the criteria of transition between smooth, two-dimensional and three-dimensional waves flow patterns along with empirical expressions of the interfacial friction factor $f_{i}$ for each flow pattern. In particular, denoting $f_{G}$ the gas to wall friction factor, it was shown that the wavy flow patterns are characterized by a ratio $f_{i} / f_{G} \gg 1$, which is interpreted as a major case of deviation from the original Taitel and Dukler [17] model. On the other hand, it is commonly assumed that for a smooth interface $f_{i}=f_{G}$. However, this statement might not be fully justified since it implies a stationary interface [30]. On the other hand, most of the experimental data available for model validation fall near the transition between stratified and wavy flow, as shown in Figure 1.

Accordingly, this paper focuses on operating conditions in a range of low gas superficial velocities, corresponding to stratified smooth gas-liquid interface, which is poorly studied, but significant for the application to gas flowlines where water accumulation is one of the issues affecting flow assurance [31]. Specifically, measurements of both pressure gradient and void fraction are here reported and compared with available models. Hence, the two-fluid model is adopted to determine the interfacial shear stress and an empirical expression of the interfacial friction factor is proposed as a closure relationship. 


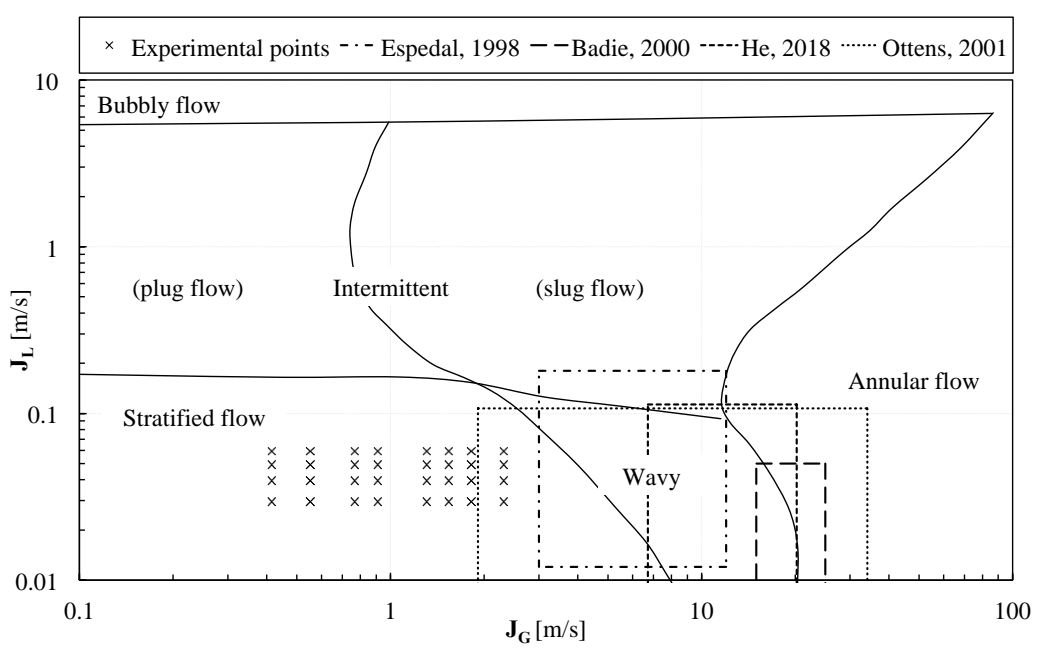

Figure 1. Mandhane map and experimental data for horizontal pipes.

Eventually, the same model was applied on a broader set of data, in which both the wavy and transition flow conditions and the inclination are taken under consideration, to confirm whether or not the correlation found can be applied to a nearly universal database, at least dealing with stratified flows.

\section{Materials and Methods}

The apparatus schematically reported in Figure 2 was used to run the experiments. It can be divided into four sections: water feed and discharge, air feed and mixer, test section, and data acquisition system. The liquid is supplied from the bottom of a $4.0 \mathrm{~m}^{3}$ tank by means of a centrifugal pump (CALPEDA $Q_{\min , \max }=0.12 / 0.75 \mathrm{~m}^{3} / \mathrm{h} ; h_{\text {min.max }}=6.5 / 20 \mathrm{~m}$ ). The volume flow rate, measured by a float-type flow meter (ASAMETRO P13-2800, 0.1-1 $\mathrm{m}^{3} / \mathrm{h}, \pm 3 \%$ full scale), is set through a valve. The two-phase flow is obtained by a mixer (Figure 3a) where compressed air is injected in the liquid flow.

The air volume flow rate is measured by float-type flow meters (Table 1), the reading of which is suitably corrected to account for pressure and temperature deviation from standard conditions. In order to reduce the measurement uncertainty in both the air and water flow rates, the flow meters have been calibrated in the considered range as reported in Colombo et al. [32].

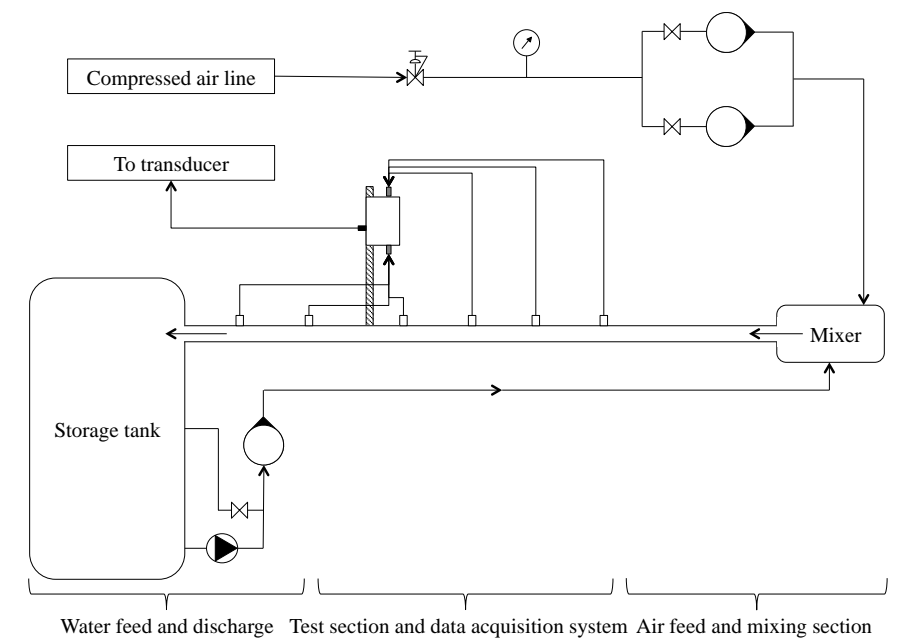

Figure 2. Layout of the experimental loop. 


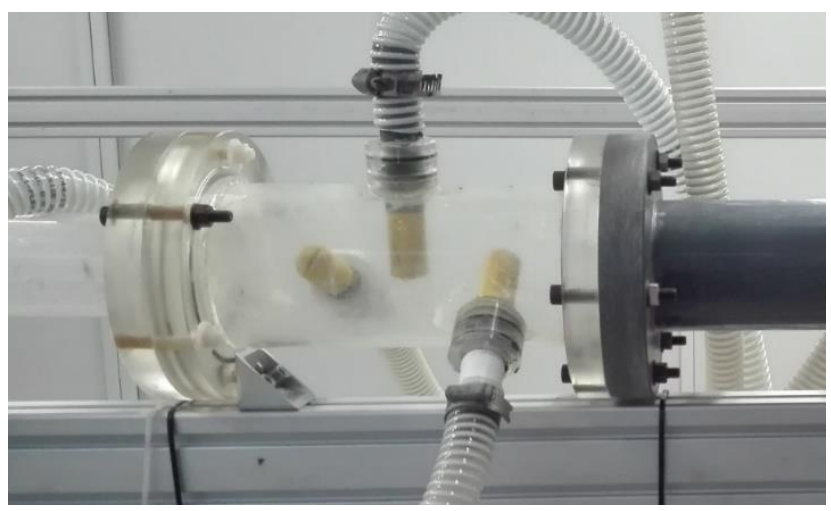

(a)

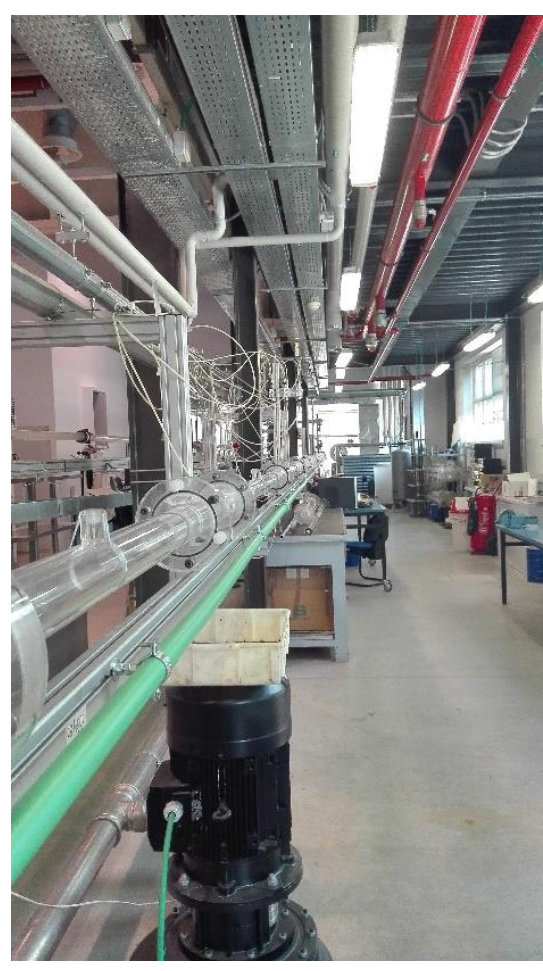

(b)

Figure 3. Detail of the mixing section (a) and of the test section (b).

Table 1. Flow-meters characteristics.

\begin{tabular}{ccc}
\hline Name & ASAMETRO P13-2800 & ASAMETRO N5-2008 \\
\hline Fluid & Water & Air \\
Range & $0.1-1 \mathrm{~m}^{3} / \mathrm{h}$ & $2.5-23.5 \mathrm{Sm}^{3} / \mathrm{h}$ \\
Error & $\pm 3 \%$ full scale & $\pm 2.5 \%$ full scale \\
$T_{\text {cal }}$ & $20{ }^{\circ} \mathrm{C}$ & $20{ }^{\circ} \mathrm{C}$ \\
$p_{\text {cal }}$ & - & $101,325 \mathrm{~Pa}$ \\
\hline
\end{tabular}

Once air and water pass through the mixing section, the resulting two-phase flow is directed to the test section, consisting of a $24 \mathrm{~m}$ long horizontal pipeline composed of 13 PMMA, $60 \mathrm{~mm}$ bore tubes, connected by means of sealed flanges, suitably designed to minimize the misalignment within a tolerance of $0.5 \mathrm{~mm}$ (Figure $3 \mathrm{~b}$ ). Furthermore, the pressure taps have been placed at a distance of at least 10 diameters from the flanges, to further dampen the disturbance caused by connections, as confirmed by the smooth behavior of the pressure along the pipeline. The loop closes on the supply tank, where the two-phase mixture is immediately separated by gravity. The test section is equipped with 4 pressure taps evenly distributed along the pipeline and connected to a differential pressure transducer.

The pressure taps are placed facing upwards as the transducer works with air only. The first tap is located $15.6 \mathrm{~m}$ downstream of the mixing section in order to consider fully developed flow conditions. All sensor signals are collected by means of a National Instruments acquisition board (1 kHz sampling frequency cf. Table 2) and processed by LabVIEW ${ }^{\circledR}$.

The operating conditions were selected in order to investigate the range shown in Figure 1. The superficial velocities are specified in Table 3. 
Table 2. Pressure transducers characteristics.

\begin{tabular}{cc}
\hline Name & SETRA 267 MR 7 \\
\hline Output & $0-5 \mathrm{~V}$ \\
Range & $0-250 / 0-1000 \mathrm{~Pa}$ \\
Fluid & Gas \\
Error & $\pm 1 \%$ full scale \\
\hline
\end{tabular}

Table 3. Superficial velocity range.

\begin{tabular}{cccc}
\hline \multicolumn{2}{c}{$J_{L}[\mathrm{~m} / \mathrm{s}]$} & \multicolumn{2}{c}{$J_{G}[\mathrm{~m} / \mathrm{s}]$} \\
\hline $\operatorname{Min}$ & $\operatorname{Max}$ & $\operatorname{Min}$ & $\operatorname{Max}$ \\
0.03 & 0.06 & 0.41 & 2.31 \\
\hline
\end{tabular}

Measurement repeatability of the pressure drop was checked by at least ten repetitions for each operating condition in different days: the minimum and maximum deviations turned out to be $1.3 \%$ and $11.5 \%$, respectively, with the highest values corresponding to flow regimes with perturbed interface (highest gas superficial velocity).

Concerning the void fraction, a resistive probe was used to measure the liquid layer height. The measuring apparatus (electrical scheme in Figure 4) is a modified version of the one developed by Kim and Kang (1992) [33] and reported also in [34] and [35]. It is a single-tip, external-electrode resistive probe that consists of: (1) a needle electrode introduced radially from above into the flow, through an open pressure tap and by means of a probe support endowed with a ruler to provide the immersion depth, and (2) a second wire, submerged through a second pressure tap into the liquid phase, that acts as a reference electrode. Both the reference electrode and the probe stem itself are very thin, so their disturbance on the liquid flow is completely negligible. The needle electrode is insulated, using a non-conductive ceramic painting, apart from the final tip that is the sensing part. The reference electrode is connected to a $+5 \mathrm{~V}$ power supply, while the needle is connected to an analogue input of the acquisition board and grounded through a resistor. The choice of connecting the reference electrode and not the probe to the $+5 \mathrm{~V}$ power supply is to avoid any possible electrowetting phenomena, with negatively charged water attracted towards the positively charged probe and consequent distortion of the measure.

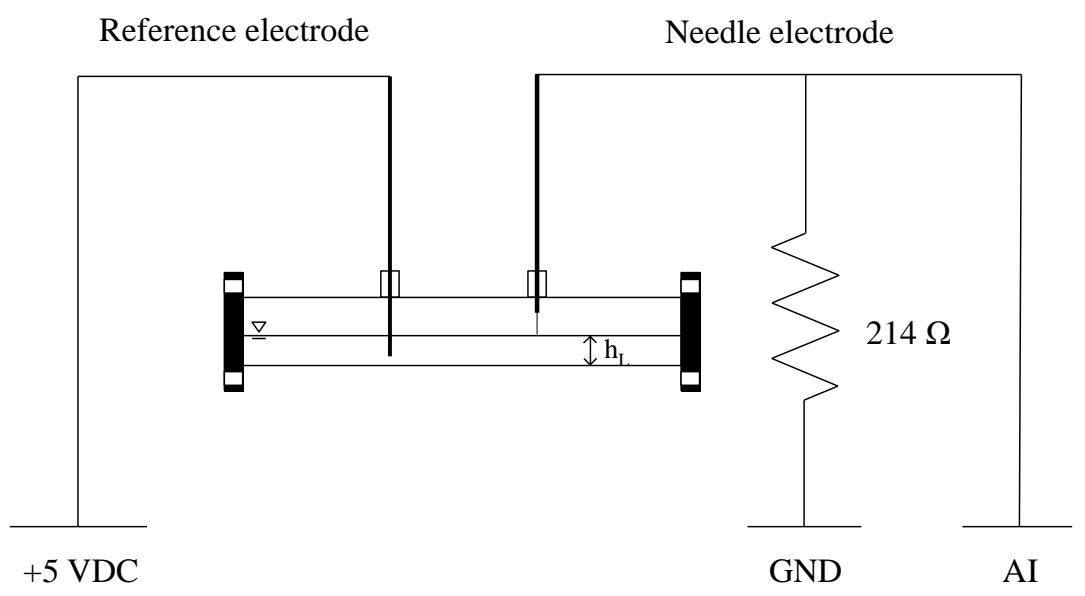

Figure 4. Resistive probe electrical scheme.

Since air is not electrically conductive, such a probe allows to sample the state density function (at a frequency of $10 \mathrm{kHz}$ ): the voltage signal is zero until the needle touches the liquid phase, then the circuit closes and the signal jumps to a positive value. A $214 \Omega$ resistor was selected as a suitable compromise between the reductions of noise and of signal amplitude; in any case the precise value 
is not of importance as the signal is only used in a bimodal way (low: air, high: water). With such a value, the signal amplitude is about $+3 \mathrm{~V}$.

It is then possible to measure the difference between the pipe inner diameter and the maximum water layer depth $h_{L}$. Accordingly, referring to Figure 5, void fraction values are obtained from Equations (1) and (2), where $\gamma$ is the angle subtended by two radii to the ends of the interface perimeter $S_{i}$.

$$
\begin{gathered}
\varepsilon=1-(\gamma-\sin \gamma) / 2 \pi \\
\gamma=2 \cos ^{-1}\left(1-2 h_{L} / D\right)
\end{gathered}
$$

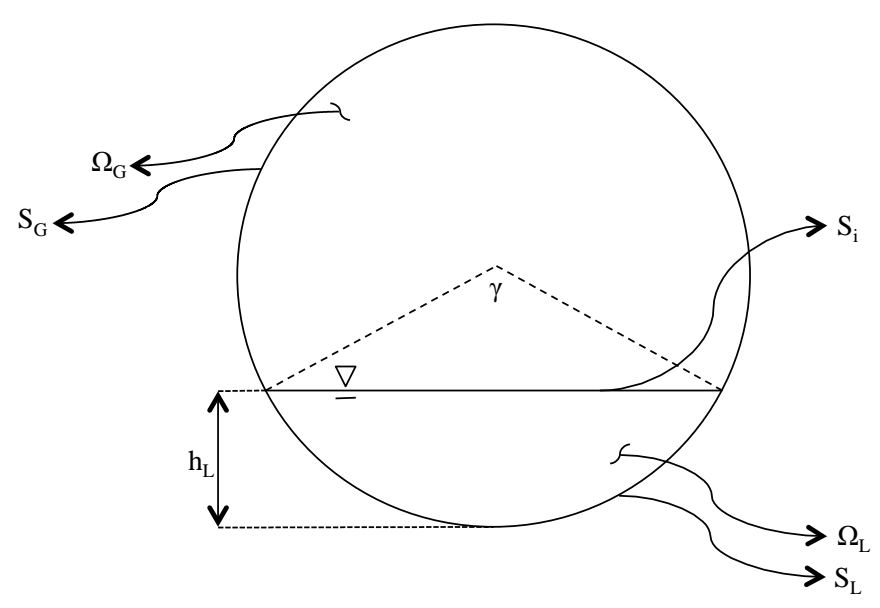

Figure 5. Cross section geometry.

The measurements were taken at two different pressure taps and at least five repetitions were done for each one, to assess repeatability. In fact, the outlined method rigorously applies with a smooth interface, which is generally confirmed by visual inspection. In any case, in the presence of weak waviness, the measurement at two different pressure taps enables the determination of the average $h_{L}$.

Concerning the accuracy of the liquid height measurement: before the tests, the probe is fully inserted in the duct so that its tip touches the duct bottom and a reference level can be evidenced on the ruler. Then the probe is retracted by the full diameter length and progressively re-inserted until the tip touches the liquid. The tip sinking is visually evaluated. Precision is quite high also when comparing measures performed by different operators and an accuracy of $0.5 \mathrm{~mm}$ can be reasonably assumed. Furthermore, an uncertainty analysis on derived quantities was performed, and the results are summarized in Table 4. The reader may refer to Appendix A for an extended discussion.

Table 4. Relative uncertainties of the main quantities.

\begin{tabular}{lcccccc}
\hline Quantity & $J_{G}$ & $J_{L}$ & $-d p / d x$ & $\varepsilon_{L}$ & Foam Quality & $\varepsilon$ \\
\hline Uncertainty [\%] & $2 \div 7$ & $2 \div 3$ & $<2$ & $2 \div 4$ & - & $<1$ \\
\hline
\end{tabular}

\section{Results and Discussion}

\subsection{Pressure Gradient}

The pressure gradient was found to linearly decrease along the flow direction, which confirms the achievement of fully developed flow conditions. Accordingly, Figure 6 reports the pressure gradient as a function of the water cut (Equation (3)):

$$
C_{L}=\frac{J_{L}}{J_{L}+J_{G}}
$$


showing a power-law dependence with an exponent equal to -1.7 , regardless the liquid superficial velocity.

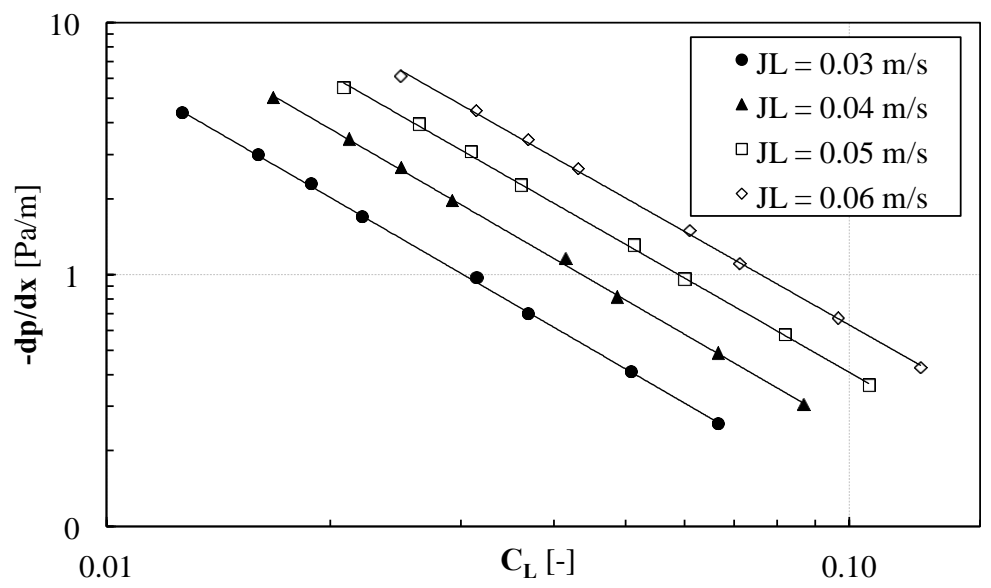

Figure 6. Pressure gradient vs. water cut.

The experimental results were then compared to the predictions of available models suited to the range of the investigated operating conditions. In particular, Tzotzi and Andritsos [29] developed the following criterion to mark the transition from smooth stratified flow to 2D wavy flow (Equation (4)):

$$
J_{G, 2-D} \geq \frac{1}{1.95} \ln \left(\frac{0.8}{J_{L, 2-D}}\right)
$$

being $J_{G, 2-D}$ and $J_{L, 2-D}$ the couple of superficial velocities marking the transition.

Based on such a criterion, about $25 \%$ of the data should correspond to stratified flow with smooth interface. On the other hand, visual observations show that the interface is usually smooth. The onset of $2 \mathrm{D}$ waviness is observed only for gas superficial velocities of about $2 \mathrm{~m} / \mathrm{s}$, i.e., about the upper limit of the investigate range, which corresponds to about $12 \%$ of the whole data.

Accordingly, the model proposed by Tzotzi and Andritsos [29] for the prediction of the pressure gradient in the case of smooth interface is the same as developed by Taitel and Dukler [17]. As mentioned in the introduction, it consists basically of a two-fluid formulation of the momentum equation in the assumption of one-dimensional fully developed steady flow with constant properties, which reads

$$
\left[p_{x}-\left(p_{x}+\frac{d p}{d x} d x\right)\right]_{G / L} \Omega_{G / L}-\tau_{G / L} S_{G / L} d x \mp \tau_{i} S_{i} d x=0
$$

Figure 7 shows a sketch of the forces accounted in the momentum balance.

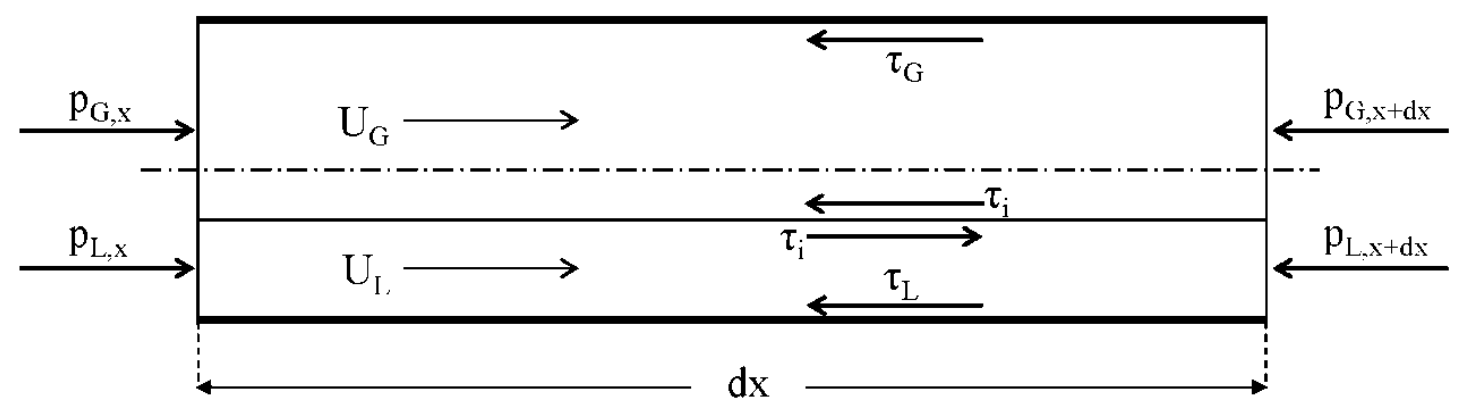

Figure 7. Two-fluid model momentum balance on a pipe element of length $\mathrm{dx}$. 
Rearranging the terms for each phase, the following system of equations results

$$
\begin{gathered}
\varepsilon\left(-\frac{d p}{d x}\right)_{G}-\tau_{G} \frac{S_{G}(\varepsilon)}{\Omega}-\tau_{i} \frac{S_{i}(\varepsilon)}{\Omega}=0 \\
(1-\varepsilon)\left(-\frac{d p}{d x}\right)_{L}-\tau_{L} \frac{S_{L}(\varepsilon)}{\Omega}+\tau_{i} \frac{S_{i}(\varepsilon)}{\Omega}=0
\end{gathered}
$$

The interaction between the phases is represented by the interfacial shear stress $\tau_{i}$, which is usually given by semi-empirical expressions involving the interfacial friction factor. In particular, according to Taitel and Dukler [17]

$$
\tau_{i}=f_{i} \frac{\rho_{G}\left(U_{G}-U_{L}\right)^{2}}{2}
$$

where for smooth interface it is assumed

$$
f_{i}=f_{G}=C_{G} R e_{G}^{-m}
$$

with $C_{G}=0.046$ and $m=0.2$ for $R e_{G}>2000$ and $C_{G}=16$ and $m=1$ otherwise.

However, as mentioned in the introduction, Equation (9) assumes that the interface is stationary regardless the relative velocity of the phases, which, according to Ullmann and Brauner [30] is one of the pitfalls causing wrong predictions even in the case the interface is smooth and plane and the flow of both phases is laminar. For this reason, these authors revised the definition of the interfacial friction factor by introducing correction factors to account for the interaction between the flows in the two layers. However, the validation of the new closure equation relies upon the database of Espedal [36], which involves a range of superficial velocities mostly corresponding to wavy flow patterns (see

\begin{tabular}{|c|c|c|c|}
\hline Model & Author/s & Correlation & Main Features \\
\hline 1 & Taitel and Dukler & $f_{i}=f_{G}$ & $\begin{array}{l}\text { It assumes there is no difference of } \\
\text { momentum transfer between a moving } \\
\text { phase and a wall and between two moving } \\
\text { phases, the interfacial friction factor is equal } \\
\text { to the gas one. }\end{array}$ \\
\hline 2 & Cohen and Hanratty & $f_{i}=0.0142$ & $\begin{array}{l}\text { Based on experiments on air-water } \\
\text { stratified-wavy flow regime in a rectangular } \\
\text { channel }(0.305 \times 0.0254 \mathrm{~m})\end{array}$ \\
\hline 3 & Agrawal et al. & $f_{i}=1.3 \operatorname{Re}_{G}^{-0.57}$ & $\begin{array}{l}\text { Based on the empirical wall friction factor } \\
\text { of Ellis and Gray, it is valid for horizontal } \\
\text { stratified smooth/wavy flow regimes. }\end{array}$ \\
\hline 4 & Kowalski & $\begin{array}{c}f_{i}=0.96 \operatorname{Re}_{S G}^{-0.52} \\
\operatorname{Re}_{S G}=\rho_{G} J_{G} D \mu_{G}^{-1}\end{array}$ & $\begin{array}{l}\text { Developed for air-water and Freon-water } \\
\text { stratified smooth flow regime at } \\
2.25-4.2 \text { bar in a } 0.051 \mathrm{~m} \text { diameter pipe. }\end{array}$ \\
\hline 5 & Crowley et al. & $f_{i}=5 f_{G}$ & $\begin{array}{l}\text { Developed as a correction of Taitel and } \\
\text { Dukler correlation when dealing with } \\
\text { stratified/slug flow transition. }\end{array}$ \\
\hline 6 & Hart et al. & $f_{i}=0.0625\left[\log \left(\frac{15}{\operatorname{Re}_{G}}+\frac{k}{3.715 D}\right)\right]^{-2}$ & $\begin{array}{l}\text { Developed for air/water, air/water/glycerol } \\
\text { flow in a } 0.051 \mathrm{~m} \text { diameter pipe, it is based } \\
\text { on the gas momentum equation only, } \\
\text { considering the liquid phase as an artificial } \\
\text { roughness } k \text {. }\end{array}$ \\
\hline
\end{tabular}
Figure 1). Moreover, most of the empirical expressions of $f_{i}$ available in the literature (see Table 5) are only validated for wavy flows up to the transition to slugs.

Table 5. Interfacial friction factor correlations.

No matter the model adopted for the interfacial shear stress, Equations (6) and (7) are solved simultaneously to determine both the pressure gradient and the void fraction. Figure 8 shows the mean absolute percentage error (MAPE) as a function of the gas superficial velocity. It is seen that MAPE 
values lower than $30 \%$ are found for $J_{G}>1.3 \mathrm{~m} / \mathrm{s}$. Below this value, the disagreement strongly increases as far as the gas superficial velocity is lowered and the liquid superficial velocity is increased. It is worth noting that the Ullman and Brauner model [30] performs better than the Taitel and Dukler [17] for $J_{G}<1.3 \mathrm{~m} / \mathrm{s}$, but MAPE remains unacceptably high for $J_{G}<0.9 \mathrm{~m} / \mathrm{s}$ and $J_{L}>0.03 \mathrm{~m} / \mathrm{s}$, suggesting that the cause of the disagreement still lies in the representation of the interfacial shear stress.

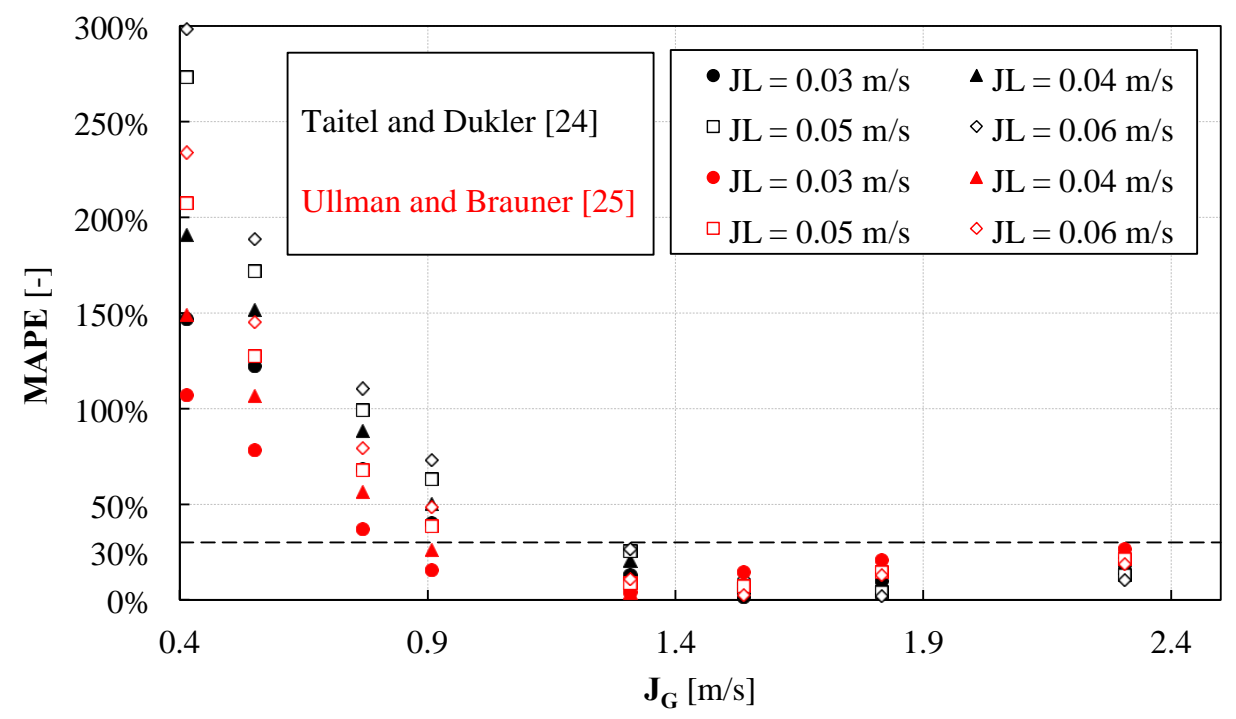

Figure 8. MAPE vs. superficial gas velocities at different superficial liquid velocities.

Accordingly, void fraction measurements were also taken in order to solve the two-fluid model, Equations (6) and (7), for the interfacial shear stress and hence provide an empirical correlation to be adopted in the considered range of the gas superficial velocities.

\subsection{Void Fraction}

Since both Taitel and Dukler [17] and Ullmann and Brauner [30] models return unsatisfactory predictions for the void fraction, especially at low air-flow rate, three correlations available in the open literature were implemented (see Table 6), i.e., Armand [37], being one of the simplest general correlations implemented for two-phase flow, Guzhov [38], as it was developed specifically for plug and stratified flow in horizontal pipes, and Rouhani [39], which is among the best predictors over a very large data set [40].

Table 6. Void fraction correlations.

\begin{tabular}{|c|c|c|c|}
\hline Model & Author/s & Correlation & Main Features \\
\hline \multicolumn{4}{|c|}{$k \varepsilon_{H}$ correlations } \\
\hline 1 & Armand & $\varepsilon=0.833 \varepsilon_{H}$ & $\begin{array}{l}\text { It is the simplest among the } k \varepsilon_{H} \text { correlations; } \\
\text { developed for air-water flow in horizontal } \\
\text { pipes, corresponds to a drift flux model with } \\
C_{0}=1.20 \text { and a zero drift velocity. }\end{array}$ \\
\hline 2 & Guzhov et al. & $\begin{array}{c}\varepsilon=0.81 \varepsilon_{H}(1-\exp (-2.2 \sqrt{F r})) \\
F r=J^{2} / g D\end{array}$ & $\begin{array}{l}\text { It was developed for stratified/intermittent flow } \\
\text { in horizontal pipes; the dependence on Froude } \\
\text { number takes into account the gravitational } \\
\text { effect at low flow rates of the mixture. }\end{array}$ \\
\hline \multicolumn{4}{|c|}{ Drift-flux correlation } \\
\hline 3 & Rouhani and Axelsson & $\begin{array}{c}\varepsilon=\frac{x}{\rho_{G}}\left[C_{0}\left(\frac{x}{\rho_{G}}+\frac{1-x}{\rho_{L}}\right)+\frac{U_{G j}}{G}\right]^{-1} \\
U_{G j}=\frac{1.18}{\sqrt{\rho_{L}}}\left[g \sigma\left(\rho_{L}-\rho_{G}\right)\right]^{0.25} \\
C_{0}=1+0.2(1-x)\end{array}$ & $\begin{array}{l}\text { It is a drift-flux correlation developed for } \\
\text { different regions of flow boiling. }\end{array}$ \\
\hline
\end{tabular}


The measured void fraction is reported against the volume quality in Figures 9 and 10, where it is also compared with some models from the literature. However, as shown in Figures 9 and 10, none of the implemented correlations satisfactorily predicted the void fraction in the whole range of superficial velocities, even though a similar trend can be found with the Armand correlation.

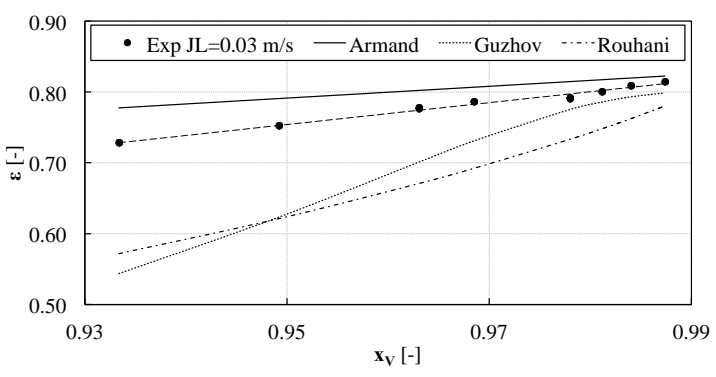

(a)

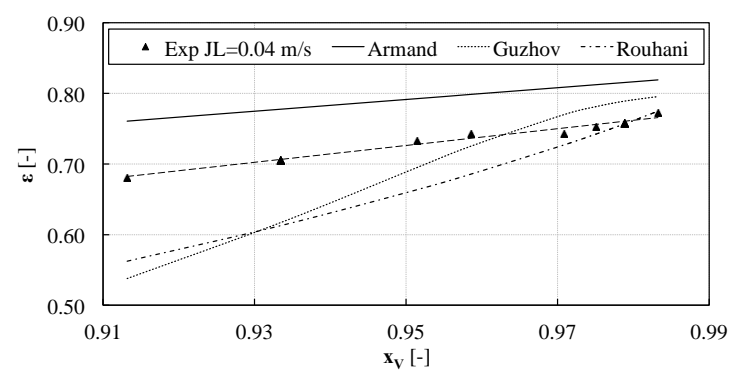

(b)

Figure 9. Experimental void fraction comparison with models (a) $J_{L}=0.03 \mathrm{~m} / \mathrm{s}$ and (b) $J_{L}=0.04 \mathrm{~m} / \mathrm{s}$.

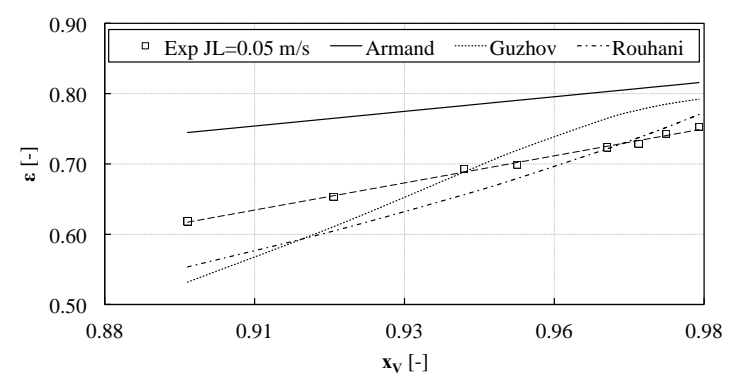

(a)

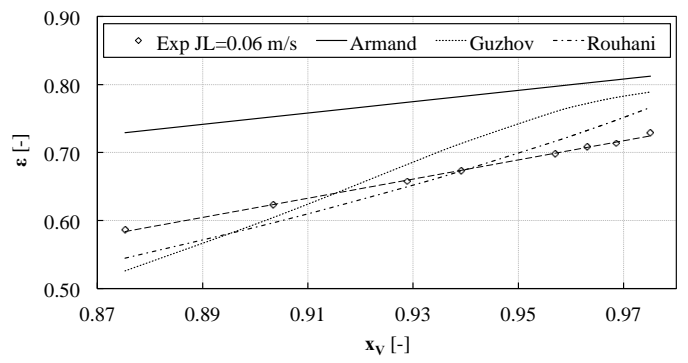

(b)

Figure 10. Experimental void fraction comparison with models $(\mathbf{a}) J_{L}=0.05 \mathrm{~m} / \mathrm{s}$ and (b) $J_{L}=0.06 \mathrm{~m} / \mathrm{s}$.

Furthermore, the agreement with the other models significantly improves as the liquid superficial velocity increases.

Hence, the collected data were processed by the drift-flux model formulated by Zuber and Findlay [41], because this approach was proved to be the most effective in modelling void fraction [40].

Accordingly, Figure 11 shows the actual velocity of the gas phase, evaluated as $U_{G}=J_{G} / \varepsilon$ against the mixture velocity $J=J_{G}+J_{L}$, for the different liquid superficial velocities.

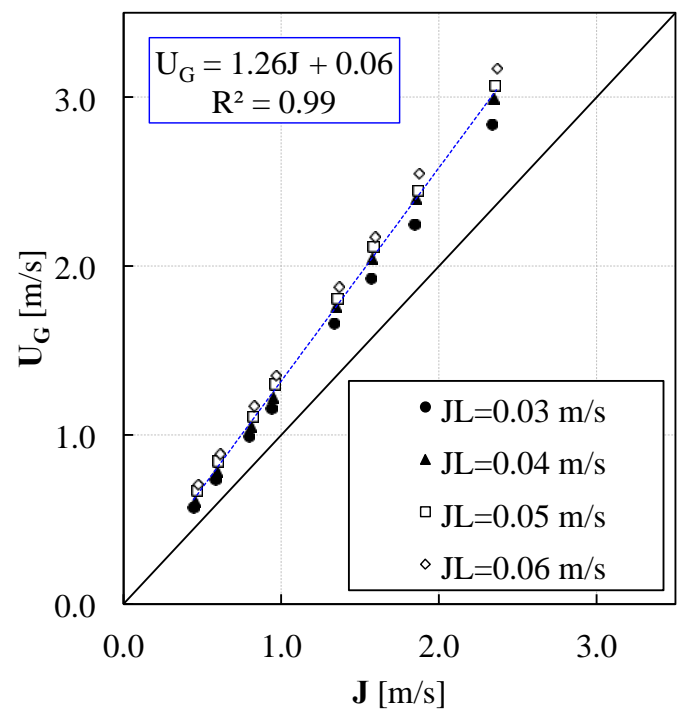

Figure 11. Effective gas velocity vs. average mixture superficial velocity. 
It is observed that each data series is linearly correlated, which is consistent with the theory. The slope of the straight line represents the so-called distribution parameter $C_{0}$, which accounts for non-uniform phase distribution on the pipe cross-section (uniform flow: $C_{0}=1$ ), and ranges from 1.20 to 1.30 as $J_{L}$ increases.

The intercept represents the weighted mean drift-velocity $U_{G J}$, which accounts for the relative velocity of the gas phase with respect to the mixture; it is almost constant, with a mean value of $0.06 \mathrm{~m} / \mathrm{s}$.

Including all the data, the drift flux model

$$
\varepsilon=x_{v} /\left(C_{0}+\frac{U_{G j}}{J}\right)
$$

with $C_{0}=1.26$ and $U_{G J}=0.06 \mathrm{~m} / \mathrm{s}$ is able to predict the data with MAPE below $8 \%$.

\subsection{Interfacial Shear}

Under the assumption of fully developed one-dimensional steady flow the pressure gradients in the two-phase are equal, the momentum equations of the two-fluid model Equations (6) and (7) were rearranged to express the interfacial shear stress as a function of the overall pressure gradient and void fraction (experimentally measured):

$$
\tau_{i}=\frac{\Omega}{S_{i}}\left[\varepsilon\left(-\frac{d p}{d x}\right)-\tau_{G} \frac{S_{G}}{\Omega}\right]
$$

The gas-wall shear stress, $\tau_{G}$, was computed according to the Churchill correlation [42] as suggested by Oliemans and Pots [43]:

$$
\begin{gathered}
\tau_{G}=\frac{1}{2} f_{G} \rho_{G} U_{G}^{2} \quad f_{G}=2\left[(8 / R e)^{12}+(a+b)^{-3 / 2}\right]^{1 / 12} \\
a=\left[2.546 \ln (7 / R e)^{-0.9}\right]^{16} b=(37530 / R e)^{16}
\end{gathered}
$$

The interfacial shear stress is plotted against the velocity difference between gas and liquid in Figure 12. A power law fitting with exponent 1.47 and a regression coefficient of 0.019 , furthermore it shows correlation coefficient equal to 0.99 .

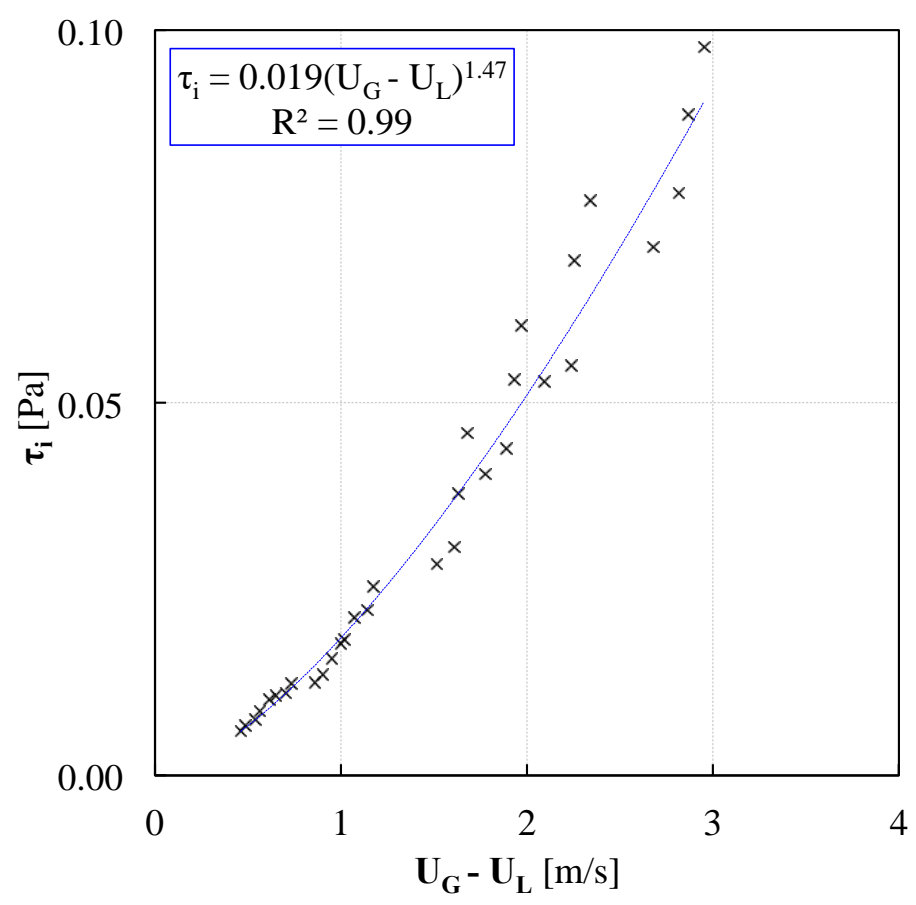

Figure 12. Interfacial shear stress vs. velocity difference. 
Accordingly, the interfacial friction factor is defined as

$$
f_{i}=\frac{2 \tau_{i}}{\rho_{G}\left(U_{G}-U_{L}\right)^{2}}
$$

and plotted against the superficial gas Reynolds number as shown in Figure 13, where it is compared with some literature models suitably developed for stratified smooth/wavy flows, namely Cohen and Hanratty [44], Agrawal [16], Kowalski [45] and Hart et al. [24]. The fitting curve is:

$$
f_{i}=2.25 R e_{S G}^{-0.53}
$$

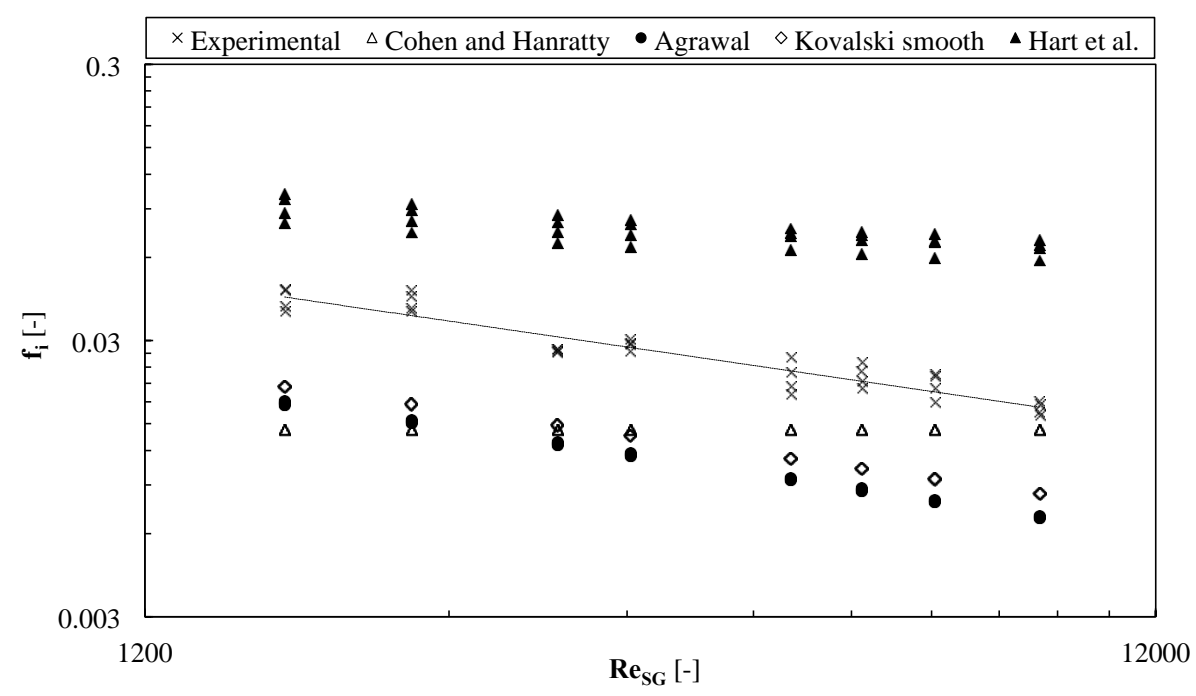

Figure 13. Interfacial friction factor vs. superficial gas Reynolds number.

Noticeably, the result falls in the mid-range of the literature models with a very similar trend compared to both Agrawal [16] and Kowalski [45] correlations, which are in the same form of a power law with the Reynolds number raised to an almost identical exponent.

\subsection{Model Extension with Espedal Database}

Eventually, further validation was performed based on the Espedal database reported in [36]. A preliminary assessment was made, since all measurements were performed with inclined pipelines: for our purposes, only data concerning slightly inclined pipes were considered, i.e., inclination angle $\vartheta$ with respect to the horizontal equal to: $-0.5^{\circ},-0.25^{\circ}$ and $-0.104^{\circ}$. The operating conditions are reported in Table 7.

Table 7. Espedal superficial velocity range for inclined tubes [36].

\begin{tabular}{lcccc}
\hline \multirow{2}{*}{ Inclination Angle $\left[^{\circ}\right]$} & \multicolumn{2}{c}{$J_{L}[\mathrm{~m} / \mathrm{s}]$} & \multicolumn{2}{c}{$J_{G}[\mathrm{~m} / \mathrm{s}]$} \\
& Min & Max & Min & Max \\
\hline-0.5 & 0.011 & 0.085 & 0.56 & 14.14 \\
-0.25 & 0.011 & 0.075 & 4.49 & 14.18 \\
-0.104 & 0.012 & 0.084 & 1.55 & 14.21 \\
\hline
\end{tabular}

The two-fluid model momentum equations were rearranged to account for pipe inclination. It resulted that the interfacial friction factor for small inclination angles does not vary considerably compared to the horizontal layout, so that Equation (14) would still apply. The Espedal data [36] were processed as indicated above in the Section "Interfacial shear" in order to evaluate the interfacial friction factor. The comparison, reported in Figure 14, shows that Equation (14) tends to overpredict 
the data, with MAPE $=35 \%$ and MPE $=-34 \%$. The data refer to the highest value of the inclination angle, which represents the worst case.

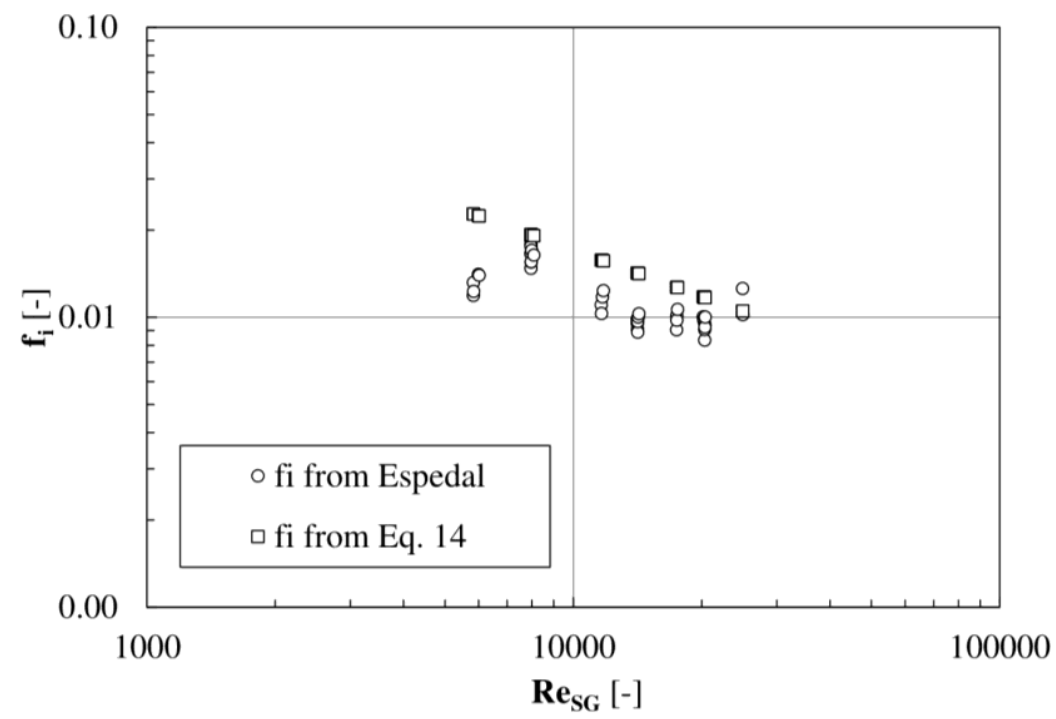

Figure 14. Interfacial friction factor vs. superficial gas Reynolds number for Espedal dataset at $\vartheta=-0.5^{\circ}$.

A correction was then introduced in Equation (14), including the Froude number, i.e., the ratio between inertia and gravity forces. For horizontal pipes $(\mathrm{Fr} \rightarrow \infty)$ the corrective term is equal to one, i.e., no correction applies.

The modified interfacial friction factor $f_{i}^{*}$ resulted as follows:

$$
f_{i}^{*}=f_{i} g(F r)=2.25 R e_{S G}^{-0.53}\left(1-\frac{C}{F r^{n}}\right) \text { with } F r=J^{2} / a b s(g D \sin \vartheta)
$$

The two unknown parameters, i.e., $C$ and $n$, were determined by regression as 1.3 and 0.21 respectively.

Figure 15 reports the comparison between Equation (15) and Espedal data [36] for the highest inclination angle. The agreement is satisfactory with MAPE $=11 \%$ and MPE $=2 \%$. However, the model is not able to explain the non-monotonic behavior derived from the experimental data.

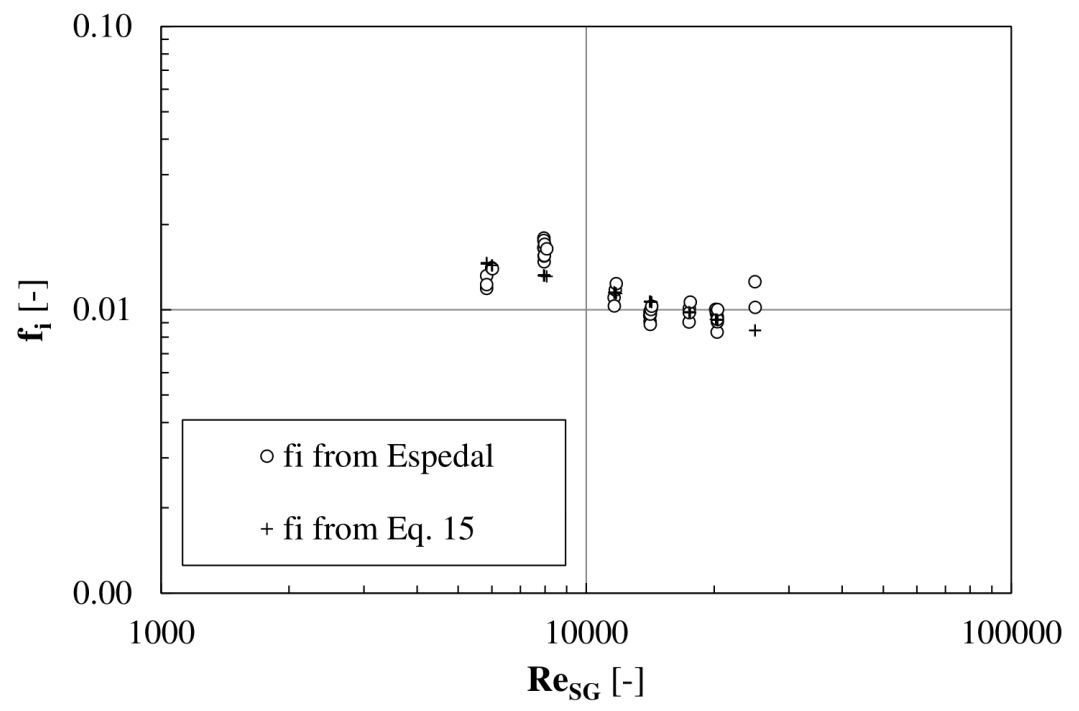

Figure 15. Interfacial friction factor vs. superficial gas Reynolds number for Espedal dataset at $\vartheta=-0.5^{\circ}$. 


\section{Conclusions}

A characterization of two-phase air-water adiabatic flows in a horizontal pipe $60 \mathrm{~mm}$ i.d. was experimentally performed, focusing on the pressure drop and void fraction in a range of water superficial velocities from 0.03 to $0.06 \mathrm{~m} / \mathrm{s}$ and air superficial velocities from 0.41 to $2.31 \mathrm{~m} / \mathrm{s}$. To the best knowledge of the authors, similar experimental conditions were poorly investigated so far in the open literature, even though they might be typically encountered in pipelines used for industrial applications. Starting with the pressure drop measurements, the comparison with two-fluid models specifically developed for stratified and wavy flow regimes, showed a fair agreement for $J_{G}>1.3 \mathrm{~m} / \mathrm{s}$, whereas below this value the deviation strongly increases as far as the gas superficial velocity is lowered and the liquid superficial velocity is increased. It was argued that such a disagreement derives from the closure equations, represented by empirical expressions of the interfacial shear, which turn out to be developed for a higher range of gas superficial velocities. Accordingly, void fraction measurements were taken by means of a resistive probe and they correlated well to the gas volume fraction by means of the drift-flux model $\left(C_{0}=1.26, U_{G J}=0.06 \mathrm{~m} / \mathrm{s}\right)$ with MAPE $<8 \%$. Hence, the momentum equations of the two-fluid model were rearranged in order to express the interfacial shear stress as a function of the overall pressure gradient and void fraction. A power-law correlation (exponent 1.47, $R^{2}=0.99$ ) between the interfacial shear stress and the gas-liquid velocity difference was found. The resulting interfacial friction factor was reported against the superficial gas Reynolds number. The comparison with some literature models shows a similar trend and values lying in the mid-range. Furthermore, the model presented was extended to slightly inclined pipelines, using the Espedal database. In particular, the model equation for the interfacial friction factor was adjusted in order to take into consideration the inclination angle through the Froude number, providing a good agreement (MAPE 11\%) with the data.

Author Contributions: Conceptualization, I.M.C. and L.P.M.C.; methodology, I.M.C. and D.F.; validation, I.M.C., and D.F.; investigation, D.F.; resources, L.P.M.C., A.L. and M.G.; writing-original draft, I.M.C. and D.F.; writing-review \& editing, L.P.M.C. and M.G.; supervision, L.P.M.C. and A.L. All authors have read and agreed to the published version of the manuscript.

Funding: This research received no external funding.

Acknowledgments: The authors thank Giorgio Sotgia for his useful suggestions. This research did not receive any specific grant from funding agencies in the public, commercial, or not-for-profit sectors.

Conflicts of Interest: The authors declare no conflict of interest.

\section{Nomenclature}

i.d. [mm or in] Inner diameter

$f[-] \quad$ Friction factor

C [-] Volume fraction (cut)

$D[\mathrm{~m}] \quad$ Pipeline diameter

$h_{L}[\mathrm{~m}] \quad$ Liquid layer height

$J[\mathrm{~m} / \mathrm{s}] \quad$ Superficial velocity

$k$ [m] Roughness

$p_{\text {cal }}[\mathrm{Pa}] \quad$ Flowmeter calibration pressure

$\operatorname{Re}[-] \quad$ Reynolds number

$S[\mathrm{~m}] \quad$ Perimeter

$T_{\text {cal }}\left[{ }^{\circ} \mathrm{C}\right] \quad$ Flowmeter calibration temperature

$U[\mathrm{~m} / \mathrm{s}] \quad$ Cross-section average velocity

$x_{v}[-] \quad$ Volumetric quality

$\varepsilon[-] \quad$ Void fraction

$\mu$ [Pa.s] Viscosity

$\rho\left[\mathrm{kg} / \mathrm{m}^{3}\right] \quad$ Density

$\tau[\mathrm{Pa}] \quad$ Shear stress

$\Omega\left[\mathrm{m}^{2}\right] \quad$ Cross section 


$\begin{array}{ll}\text { Subscripts } & \\ \text { G } & \text { Gas } \\ \text { I } & \text { Interface } \\ \text { L } & \text { Liquid }\end{array}$

\section{Appendix A -Extended Uncertainty Propagation Analysis}

\section{Appendix A.1. Flow Rates and Velocities Uncertainties}

The value of air-flow rate in the pipeline depends on a set of independent measured quantities: the set value of the flowmeter $\dot{V}_{G, c a l}$, the flowmeter working pressure $p_{w o r k}$, the average duct pressure $p_{d u c t}$ and temperature $T_{\text {duct }}$. Therefore, partial derivatives with respect to these variables have to be computed and evaluated at the known values of the measured quantities. Throughout Appendix A E stands for uncertainty.

$$
\begin{aligned}
& \Delta y=\sqrt{\sum_{i=1}^{n}\left(\frac{\partial f}{\partial x_{i}} \Delta x_{i}\right)^{2}} \\
& \dot{V}_{d u c t}=\dot{V}_{c a l} \sqrt{\frac{p_{c a l} \cdot p_{\text {work }}}{p_{d u c t}^{2}}} \sqrt{\frac{T_{d u c t}}{T_{c a l}}} \\
& E_{\dot{V}_{G}}=\sqrt{\left(\frac{\partial \dot{V}_{G}}{\partial \dot{V}_{G, \text { cal }}} E_{\dot{V}_{G, \text { cal }}}\right)^{2}+\left(\frac{\partial \dot{V}_{G}}{\partial p_{\text {work }}} E_{p_{\text {work }}}\right)^{2}+\left(\frac{\partial \dot{V}_{G}}{\partial p_{\text {duct }}} E_{p_{\text {duct }}}\right)^{2}+\left(\frac{\partial \dot{V}_{G}}{\partial T_{\text {duct }}} E_{T_{\text {duct }}}\right)^{2}} \\
& \frac{\partial \dot{V}_{G}}{\partial \dot{V}_{G, \text { cal }}}=\sqrt{\frac{p_{\text {cal }} p_{\text {woork }}}{p_{\text {duct }}^{2}}} \sqrt{\frac{T_{\text {duct }}}{T_{\text {cal }}}}(i) \quad \frac{\partial \dot{V}_{G}}{\partial p_{\text {work }}}=\frac{\dot{V}_{G, \text { cal }}}{2} \sqrt{\frac{p_{\text {cal }}}{p_{\text {woork }} p_{\text {duct }}^{2}}} \sqrt{\frac{T_{\text {duct }}}{T_{\text {cal }}}}(i i) \\
& \frac{\partial \dot{V}_{G}}{\partial p_{\text {duct }}}=-\frac{\dot{V}_{G, \text { cal }}}{p_{\text {duct }}^{2}} \sqrt{p_{\text {cal }} p_{\text {work }}} \sqrt{\frac{T_{\text {duct }}}{T_{\text {cal }}}}(\text { iii }) \\
& \frac{\partial \dot{V}_{G}}{\partial T_{d u c t}}=\frac{\dot{V}_{G, c a l}}{2} \sqrt{\frac{p_{\text {cal }} p_{\text {work }}}{p_{d u c t}^{2}}} \sqrt{\frac{1}{T_{\text {cal }} T_{\text {duct }}}}
\end{aligned}
$$

Finally, superficial velocities uncertainties, i.e., $E_{J G}, E_{J L}$ and $E_{J}$ are computed according to the same method resulting in the following:

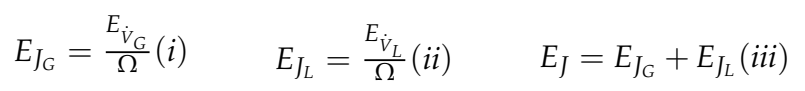

Pressure uncertainty

Pressure measures are obtained as time averaged value over an acquisition time interval $t$, and therefore the uncertainty $E_{p i}$ is computed as:

$$
E_{P, i}=\frac{E_{\text {transducer }}}{\sqrt{f_{s} t}}
$$

where $f_{s}$ is the board sampling frequency, so that the product $f_{s} \cdot t$ is the number of samples $n$.

Regarding the uncertainty on the pressure gradient, it is taken equal to the value of the standard error associated to the angular coefficient of the linear regression computed by Microsoft ${ }^{\circledR}$ Excel.

$$
\sigma_{b}=\sqrt{\frac{\sum_{i}^{n}\left(y_{i}-\hat{y}_{i}\right)^{2}}{(n-2) \sum_{i}^{n}\left(x_{i}-\bar{x}_{i}\right)^{2}}}
$$

Liquid holdup uncertainty

The liquid loading is a function of the liquid depth only as here below reported:

$$
\frac{d \varepsilon_{L}}{d h_{L}}=\frac{d \varepsilon_{L}}{d \gamma} \frac{d \gamma}{d h_{L}}=\frac{4 / D}{\sqrt{1-\left(1-2 \frac{h_{L}}{D}\right)^{2}}} \frac{1-\cos \gamma}{2 \pi}(i) \quad E_{\varepsilon_{L}}=\left|\frac{d \varepsilon_{L}}{d h_{L}}\right| E_{h_{L}}(i i)
$$




\section{References}

1. Brennen, C.E. Introduction to Multiphase Flow. In Fundamentals of Multiphase Flow; Cambridge University Press: Cambridge, UK, 2005; Chapter 1.

2. Ranade, V.V.Computational Flow Modelling for Chemical Reactor Engineering. In Process Systems Engineering; Elsevier: Amsterdam, The Netherlands, 2002; Volume 5.

3. Mandhane, J.M.; Gregory, G.A.; Aziz, K. A flow pattern map for gas-liquid flow in horizontal pipes. Int. J. Multiph. Flow 1974, 1, 537-553. [CrossRef]

4. Mokhatab SPoe, W.A.; Mak, J.Y. Raw Gas Transmission. In Handbook of Natural Gas Transmission and Processing, 3rd ed.; Elsevier: Amsterdam, The Netherlands, 2015; Chapter 2.

5. Byeonggeon, B.; Taehwan, A.; Jaejun, J.; Kyungdoo, K.; Byongjo, Y. Characteristics of an interfacial wave in a horizontal air-water stratified flow. Int. J. Multiph. Flow 2017, 97, 197-205.

6. Spedding, P.L.; Nguyen, V.T. Regime map for air water two-phase flow. Chem. Eng. Sci. 1979, 35, 779-793. [CrossRef]

7. Andritsos, N.; Hanratty, T.J. Influence of interfacial waves in stratified gas-liquid flow. AIChE J. 1987, 33, 444-454. [CrossRef]

8. Tzotzi, C.; Bontozoglou, V.; Vlachogiannnis, M.; Andritsos, N. Effect of fluid properties on flow patterns in two-phase gas-liquid flow in horizontal and downward pipes. Ind. Eng. Chem. Res. 2011, 50, 645-655. [CrossRef]

9. Volkart, P. The Mechanism of Air Bubble Entrainment in Self-Aerated Flow. Int. J. Multiph. Flow 1980, 6, 411-423. [CrossRef]

10. Lin, P.Y.; Hanratty, T.J. Effect of pipe diameter on flow patterns for air-water flow in horizontal. Int. J. Multiph. Flow 1987, 13, 549-563. [CrossRef]

11. Fernandino, M.; Ytrehus, T. Determination of flow sub-regimes in stratified air-water channel flow using LDV spectra. Int. J. Multiph. Flow 2006, 32, 436-446. [CrossRef]

12. Hudaya, A.Z.; Kuntoro, H.Y.; Dinaryanto, O. Indarto and Deendarlianto, Experimental investigation on the interfacial characteristics of stratified air-water two phase flow in a horizontal pipe. AIP Conf. Proc. 2016, 1737, 040012.

13. Setyawan, A. Indarto, Deendarlianto, The effect of the fluid properties on the wave velocity and wave frequency of gas-liquid annular two-phase flow in a horizontal pipe. Exp. Therm. Fluid Sci. 2016, 71, $25-41$. [CrossRef]

14. Wallis, G.B. One-Dimensional Two-Phase Flow; McGraw-Hill: New York, NY, USA, 1969.

15. Govier, G.W.; Aziz, K. Flow of Complex Mixtures in Pipes; Van Nostrand-Reinhold Co.: New York, NY, USA, 1972.

16. Agrawal, S.S.; Gregory, G.A.; Govier, G.W. An analysis of horizontal stratified two-phase flow in pipes. Can. J. Chem. Eng. 1973, 51, 280. [CrossRef]

17. Taitel, Y.; Dukler, A.E. A model for predicting flow regime transitions in horizontal and near horizontal gas-liquid flow. AIChE J. 1976, 22, 47-55. [CrossRef]

18. Andritsos, N.; Hanratty, T.J. Interfacial instabilities for horizontal gas-liquid in pipelines. Int. J. Multiph. Flow 1987, 13, 583-603. [CrossRef]

19. Ayati, A.A.; Vollestad, P.; Jensen, A. Detailed measurements of interfacial dynamics in air-water pipe flow. Procedia Iutam 2018, 26, 59-69. [CrossRef]

20. Berthelsen, P.A.; Ytrehus, T. Calculations of stratified wavy two-phase flow in pipes. Int. J. Multiph. Flow 2005, 31, 571-592. [CrossRef]

21. Deendarlinato, R.A.; Widyatama, A.; Dinaryanto, O.; Widyaparaga, A. Indarto, Experimental study on the hydrodynamic behaviour of gas-liquid air-water two-phase flow near the transition to slug flow in horizontal pipes. Int. J. Heat Mass Transfer. 2019, 130, 187-203. [CrossRef]

22. Ahn, T.H.; Yun, B.J.; Jeong, A.J. Void fraction prediction for separated flows in the nearly horizontal tubes. Nucl. Eng. Technol. 2015, 47, 669-677. [CrossRef]

23. Badie, S.; Hale, C.P.; Lawrence, C.J.; Hewitt, G.F. Pressure gradient and holdup in horizontal two-phase gas-liquid flows with low liquid loading. Int. J. Multiph. Flow 2000, 26, 1525-1543. [CrossRef] 
24. Hart, J.; Hamersma, P.J.; Fortuin, J.M. Correlations predicting frictional pressure drop and liquid holdup during horizontal gas-liquid pipe flow with a small liquid holdup. Int. J. Multiph. Flow 1989, 15, 947-964. [CrossRef]

25. Paras, S.V.; Vlachos, N.A.; Karabelas, A.J. Liquid layer characteristics in stratified-atomization flow. Int. J. Multiph. Flow 1994, 20, 939-956. [CrossRef]

26. Chen, X.T.; Cai, X.D.; Brill, J.P. Gas-liquid stratified-wavy flow in horizontal pipelines. J. Energy Resour. Technol. 1997, 119, 209-216. [CrossRef]

27. Ottens, M.; Hoefsloot, C.J.; Hamersma, P.J. Correlations predicting liquid hold-up and pressure gradient in steady-state (nearly) horizontal co-current gas-liquid pipe flow. Chem. Eng. Res. Des. 2001, 79, 581-592. [CrossRef]

28. Lim, L.G.; Pao, W.K.S.; Hamid, N.H.; Tang, T.B. Design of Helical Capacitance Sensor for Holdup Measurements in Two-Phase Stratified Flow: A Sinusoidal Function Approach. Sensors 2016, 16, 1032. [CrossRef] [PubMed]

29. Tzotzi, C.; Andritsos, N. Interfacial shear stress in wavy stratified gas-liquid flow in horizontal pipes. Int. J. Multiph. Flow 2013, 54, 43-54. [CrossRef]

30. Ullman, A.; Brauner, N. Closure relations for two-fluid models for two-phase stratified smooth and stratified wavy flows. Int. J. Multiph. Flow 2006, 32, 82-105. [CrossRef]

31. Sloan, D.; Koh, C.A.; Sum, A.K.; McMullen, N.D.; Shoup, G.; Ballard, A.L.; Palermo, T. Natural Gas Hydrates in Flow Assurance; Gulf Professional Publishing, Elsevier: Amsterdam, The Netherlands, 2011.

32. Colombo, L.; Carraretto, I.; Di Lullo, A.; Passucci, C.; Allegrucci, A. Experimental study of aqueous foam generation and transport in a horizontal pipe for deliquification purposes. Exp. Therm. Fluid Sci. 2019, 98, 369-380. [CrossRef]

33. Kang, H.C.; Kim, M.H. The development of a flush-wire probe and calibration method for measuring liquid film thickness. J. Multiph. Flow 1992, 18, 423-437. [CrossRef]

34. Ceccio, S.L.; George, D.L. A review of electrical impedance techniques for the measurement of multiphase flows. J. Fluids Eng. 1996, 118, 391-399. [CrossRef]

35. He, D.; Chen, S.; Bai, B. Void fraction measurement of stratified gas-liquid flow based on multi-wire capacitance probe. Exp. Therm. Fluid Sci. 2019, 10, 61-73. [CrossRef]

36. Espedal, M. An Experimental Investigation of Stratified Two-Phase Pipe Flow at Small Inclinations. Ph.D. Thesis, Norges Teknisk-Naturvitenskaplige Universitet, Trondheim, Norway, 1998.

37. Armand, A.A. The resistance during the movement of a two-phase system in horizontal pipes. Izvestiia Vsesoiuznyi Teplotekhnicheskii Institut 1946, 1, 16-23.

38. Guzhov, A.L.; Mamayev, V.A.; Odishariya, G.E. A study of transportation in gas liquid systems. In Proceedings of the 10th International Gas Union Conference, Hamburg, Germany, 1967.

39. Rouhani, S.Z.; Axelsson, E. Calculation of void volume fraction in the sub cooled and quality boiling regions. Int. J. Heat Mass Transfer 1970, 13, 383-393. [CrossRef]

40. Woldesemayat, M.A.; Ghajar, A.J. Comparison of void fraction correlations for different flow patterns in horizontal and upward inclined pipes. Int. J. Multiph. Flow 2007, 33, 347-370. [CrossRef]

41. Zuber, N.; Findlay, J.A. Average volumetric concentration in two-phase flow systems. J. Heat Transfer 1965, 87, 453-468. [CrossRef]

42. Churchill, S.W. Friction factor equation spans all fluid-flow regimes. Chem. Eng. J. 1977, 84, 91-92.

43. Oliemans, R.V.A.; Pots, B.F.M. Gas-liquid transport in ducts. In Multiphase Flow Handbook; Clayton, T., Ed.; CRC Press: Boca Raton, FL, USA, 2006; Chapter 2.

44. Cohen, L.S.; Hanratty, T.J. Effects of waves at a gas-liquid interface on a turbulent air flow. J. Fluid Mech. 1968, 31, 467-469. [CrossRef]

45. Kowalski, J.E. Wall and interfacial shear stress in stratified flow in a horizontal pipe. AIChE J. 1987, 33, 274-281. [CrossRef]

(C) 2020 by the authors. Licensee MDPI, Basel, Switzerland. This article is an open access article distributed under the terms and conditions of the Creative Commons Attribution (CC BY) license (http://creativecommons.org/licenses/by/4.0/). 